\title{
Efficiency Analysis Of Ground Source Heat Pump In Energy-Saving Building Based on Multi Target \& Multi Constraint
}

\author{
Bai Bing ${ }^{1, a *}$, Wang Chongen ${ }^{2}$ \\ ${ }^{I}$ Taiyuan University of Technology, No. 79 Yingze West Street, Taiyuan City, Shanxi Province, \\ China \\ ${ }^{2}$ Taiyuan University of Technology, No. 79 Yingze West Street, Taiyuan City, Shanxi Province, \\ China \\ a m15035751812@163.com
}

Keywords: building energy-saving technology, ground source heat pump, central heating, dynamic annual cost

\begin{abstract}
China is a country with a large amount of buildings with astonishing annual building energy consumption, so it becomes necessary to popularize building energy-saving technology. Though ground source heat pump (GSHP) technology is able to considerably reduce energy consumption of buildings' heating, the high initial cost of it becomes a barrier during the process of its popularization. Based on economic dynamic annual cost method, this paper compares the economical efficiency of GSHP system and central heating system. It is concluded that GSHP technology has a higher economical efficiency in the long term which can promote the popularization of building energy-saving technology.
\end{abstract}

\section{Introduction}

Building energy consumption is the energy produced during the process of using the building. It includes the electrical energy consumption of appliances, the energy consumption of air conditions, heaters, cooking as well as lighting, etc. among which the energy consumption of heaters and air conditions accounts for $60 \% \sim 70 \%$.

China is a country with a large number of buildings. According to the latest incomplete statistics, China's building areas increase by 18 to 20 hundred million square meters a year, which is more than the total increasing building areas of developed countries, besides, new residential buildings account for a substantial part of areas. Buildings in China cover more than 400 hundred million square meters, however, energy- saving buildings cover only 4 hundred million square meters which accounts for $1 \%$ of the total building areas, and $99 \%$ are all buildings with high energy consumption. The proportion of buildings' total energy consumption in China's total energy consumption is already above $27 \%$ [1].

Since 1990s, China has studied and applied Ground Source Heat Pump (GSHP) system. In 2000, GSHP was popularized throughout China, and especially from 2005, the application of GSHP was significantly accelerated. Nevertheless, the traditional central heating is still popular in North China, which makes it difficult for GSHP being spread. Through the investigation of a certain residential area, this paper adopted economic method to estimate GSHP's economical efficiency.

\section{The application of GSHP in North China's residential areas}

Modern moma (MOMA) residential area in Beijing applies GSHP successfully. Due to its large-scale of GSHP, unique architectural design as well as environmental friendly community construction, Beijing's MOMA residential area joins the world famous buildings, besides, it was named as one of the seven greatest architectural wonders of the world in 2006 by American Popular Science and one of the ten architectural miracles of the world in 2007 by American Time.

MOMA residential area adopts a compound system, i.e. GSHP + cooling tower + furnace. This system is of non-full loads for most of its working hours and GSHP is able to ensure $55 \%$ of the peak loads, which bears about $85 \%$ of the total loads in one year. In this way, the initial cost could be reduced considerably and at the same time, it could balance soil's total quantities of absorbing and releasing heat 
all the year round which prevents soil's imbalance. Thus, MOMA adopts GSHP compound system that has a total load with two parts, one is base load and the other one is peak load. Base loads, bore by GSHP, account for 55\% 60\% of the total heat loads; while, peak loads, bore by cooling tower and furnace, account for 35\% 40\% of the total heat loads. It ensures a high comfortable demand --maintaining the temperature of every room as $20 \sim 26^{\circ} \mathrm{C}$ and humidity as $30 \% \sim 70 \%$ all the year round, in addition, its energy consumption is only $1 / 3$ of that of Chinese general residential areas which have the same comfortable degree.

\section{The evaluation indices of economical efficiency analysis}

Efficiency analysis of GSHP system and central heating system is a multi target and multi constraint problem, in order to reduce the constraints, we reference as follow.

$$
\begin{aligned}
& \min f(x)=f\left(x_{1}, x_{2}, \ldots, x_{n}\right) \\
& \text { s.t. } R_{j}\left(x_{1}, x_{2}, \ldots, x_{n}\right) \leq 0(j=1,2, \ldots, m) \\
& K S(\rho, x)=\frac{1}{\rho} \ln \left[\sum_{j=1}^{m} \exp \left(\rho \bullet g_{j}(x)\right]\right.
\end{aligned}
$$

Through the given economic and thermal conditions of a certain residential area in North China, this paper uses dynamic annual cost method to compare the economical efficiency indices of two systems (other thermal conditions are the same) --- the central heating system and GSHP system applied for providing heating in winter.

\section{Dynamic annual cost}

Dynamic annual cost method is allocating the prevent value of the initial cost to every year according to its time value, and the final result is gotten from which adds the annual operation cost. The best program is the one with the least annual cost. This method is characterized by estimating every program's economical efficiency simply, visually, objectively and synthetically.

The formula of dynamic annual cost is given as follow:

$$
A W=\frac{i}{1-(1+i)^{-n}} \times C_{0}+C
$$

$\boldsymbol{A} \boldsymbol{W}$-- Annual cost (ten thousand Yuan);

$C_{0}$-- Initial cost, including the cost of civil work, equipments purchase and installment cost, other cost as well (ten thousand Yuan);

$i$-- Interest rate, usually $10 \%$;

$n$-- Life span (year);

$C$-- The annual operation cost (ten thousand Yuan), including service cost (i.e. water, electricity and energy cost), maintenance cost, labor cost and so on.

\section{The given parameters}

i) Economical efficiency analysis parameters

The cost of ground source heat pump is calculated by $0.8^{\text {yuan } / w}$ according to its refrigerating capacity [2]. The installment fee of heat pump is calculated by $15 \%$ of the system's equipment fee; the cost of drilling holes or wells is calculated by $100 \mathrm{yuan} / m$. Considering every $1.163 \mathrm{MW}$ cooling load needs $100 \mathrm{~m}^{2}$, the area of refrigeration room covers about $0.6 \%-09 \%$ of the whole building's area [3]. The yearly GSHP system's maintenance fee is calculated by 5 thousand Yuan; municipal central heating 
system's fee is calculated by 8 thousand Yuan. Labor cost is calculated based on 2 people needed in GSHP system and 4 people needed in municipal central heating system, and the salary is $1000-1500$ Yuan a month.

ii) The general situation of the program and calculation parameters

1) The general situation of the program and climate conditions

The building area of a certain residential area in Beijing is $24500 \mathrm{~m}^{2}$, the index of space heating load is $62.8 \mathrm{~W} / \mathrm{m}^{2}$ and the total heat load is $1538.25 \mathrm{KW}$. The design temperature of indoor heating is $18^{\circ} \mathrm{C}$ and the calculation of outdoor temperature of the heating room should refer to Beijing's Heating Regulations as well as the average value of actual statistics.

2) Calculation objects

Residential buildings in the residential area are selected as calculation objects and the index of space heating load is $62.8 \mathrm{~W} / \mathrm{m}^{2}$.

3) Energy consumption indices

Electricity price for residents: $0.5 y u a n / k w \bullet h$, water price: 4.0 yuan / dun .

4) Fee scale

According to Beijing's fee scale, the fee scale of municipal central heating is $24 \mathrm{yuan} / \mathrm{m}^{2}$ for each quarter; account opening fee is calculated by 25 yuan $/ \mathrm{m}^{2}$.

\section{The economical efficiency analysis and calculation of GSHP}

We compare ground source heat pump system and municipal central heating system, and then analyze their economical efficiency.

Step 1: The general situation of the program and the given parameters (see above)

Step 2: Calculate the economical parameters of GSHP system and municipal central heating system respectively.

i) Initial cost of GSHP system = equipment cost + installment cost + drilling holes cost + civil work cost;

Initial cost of municipal central heating system $=$ installment cost + civil work cost + account opening cost + radiator cost + pipes cost + labor cost;

Table 1: The calculation of initial cost

\begin{tabular}{|c|c|c|}
\hline Item & GSHP system & $\begin{array}{c}\text { Municipal central heating } \\
\text { system }\end{array}$ \\
\hline Equipment cost & 109.89 & 188.97 \\
\hline Installment cost & 46.11 & 102.61 \\
\hline Civil work cost & 17.63 & 38.22 \\
\hline Drilling holes cost & 429.624 & 329.8 \\
\hline Total initial cost & 603.254 & 0 \\
\hline
\end{tabular}

* The equipment cost of municipal central heating system is the result of adding radiator cost, pipes cost as well as labor cost

As can be seen from table 1, GSHP system's initial cost is a little higher than that of municipal central heating system and the incremental cost is $111.6^{\text {yuan } / m^{2}}$, which is still in costumers' affordable range.

ii) The annual operation cost $=$ annual service cost + maintenance cost + labor cost;

Annual service cost mainly includes water, electricity and fuel cost.

Electricity cost $=$ actual power consumption * electricity price;

Water cost $=$ water consumption $*$ water price;

Energy cost $=$ amount of energy $*$ energy price. 
Table 2: The measured values of electricity and water consumption

\begin{tabular}{|c|c|c|}
\hline & $\begin{array}{c}\text { Annual electricity } \\
\text { consumption }(\mathrm{k} w h)\end{array}$ & $\begin{array}{c}\text { Water consumption } \\
\left(\mathrm{m}^{3}\right)\end{array}$ \\
\hline GSHP system & 243553 & 12464 \\
\hline $\begin{array}{c}\text { Municipal central heating } \\
\text { system }\end{array}$ & 0 & 0 \\
\hline
\end{tabular}

Annual service cost $=$ electricity cost + water cost + energy cost;

GSHP system's service cost: $243553 * 0.5+12464 * 4=171632$

Municipal central heating system's cost: $24500 * 24=588000$

Table 3: Annual operation cost (ten thousand Yuan)

\begin{tabular}{|c|c|c|c|c|}
\hline & $\begin{array}{c}\text { Annual } \\
\text { service cost }\end{array}$ & $\begin{array}{c}\text { Annual } \\
\text { maintenance } \\
\text { cost }\end{array}$ & $\begin{array}{c}\text { Annual labor } \\
\text { cost }\end{array}$ & $\begin{array}{c}\text { Annual } \\
\text { operation cost }\end{array}$ \\
\hline GSHP system & 17.163 & 1.657 & 3.48 & 22.3 \\
\hline $\begin{array}{c}\text { Municipal } \\
\text { central heating } \\
\text { system }\end{array}$ & 58.800 & 2.652 & 6.96 & 68.41 \\
\hline
\end{tabular}

Step 3: Analyze the economical efficiency of GSHP system and municipal central heating system; the total cost consists of two parts: initial cost and annual operation cost. Calculate the annual cost of GSHP system and municipal central heating system respectively.

Considering different life spans of GSHP system and municipal central heating system, we calculate the annual cost according to their life span respectively; the life span of GSHP system is 50 years, and the life span of municipal central heating system is 20 years.

Table 4: Dynamic annual cost

\begin{tabular}{|c|c|c|}
\hline & GSHP system & $\begin{array}{c}\text { Municipal central heating } \\
\text { system }\end{array}$ \\
\hline Initial cost & 603.254 & 329.8 \\
\hline $\begin{array}{c}\text { Present value of initial } \\
\text { cost }\end{array}$ & 60.808 & 38.74 \\
\hline $\begin{array}{c}\text { Annual operation cost } \\
\text { Dynamic annual cost }\end{array}$ & 22.3 & 68.41 \\
\hline
\end{tabular}

\section{Conclusions of the comparison}

Conclusions are made based on those tables above:

i) The dynamic annual cost of GSHP system is 24.04 ten thousand Yuan lower than that of municipal central heating system.

ii) When the cost saved from this dynamic annual cost is reflected on heating cost, it shows that applying GSHP system is 9.81 yuan $/ \mathrm{m}^{2}$ cheaper than applying municipal central heating system for a quarter. 
iii) Comparing Beijing's average heating cost of GSHP system and that of municipal central heating system, i.e. comparing $20 \mathrm{yuan} / \mathrm{m}^{2}$ and $24 \mathrm{yuan} / \mathrm{m}^{2}$ for each quarter, we find that homeowners can only get $43.5 \%$ of the total saved cost.

\section{Conclusions}

Though the initial cost of GSHP technology is relatively high, the ongoing operation can save a great amount of energy and money. The obstructions that spreading GSHP technology in North China faces are listed as follow:

i) High technical barrier of GSHP technology makes developers choose municipal central heating system which is much easier to install for the purpose of saving time and cost.

ii) The thermotechnical districts in North China are cold or extreme cold districts where the highest temperature in summer is relatively low, which makes it unnecessary to use refrigeration facilities.

Hence, if GSHP system with a cooling function is only used for heating in winter, the equipment cost is increased invisibly.

iii) The proportion of benefits that homeowners would get is too small to become a direct reason for them to increase their initial cost.

\section{References}

[1] Parson. R. ASHRAE Handbook - Fundamentals. Atlanta (USA): ASHRAE Ine. 1985, ChaPter 28.

[2]Guo Erbao. The study of the application of ground source heat pump in Hefei. Hefei university of technology, 2009

[3]Caishi Cheng. The plan of energy saving and emission reduction issued by state council focuses mo re on building energy saving. $<$ http://www.cusdn.org.cn/news_detail.php?md=188\&epid=200\&id=215968>.2012-09-18.

[4] Kretesslmeier G, Stemhuaser R. Systematic control design by optimizing a vector performance index [A].In Proceeedings of the International Federation of Automatic Systems [C]. ZurichSwitzerland Pergamon Press, 1979

[5] Pei M, He W D. Fitting characteristics of K S function and its application[A].In: proceedings of 4 International Symposium on Advanced Manufacturing technology Computer Integrated Manufacturing [C]. Shanghai: Tongji University Press ,1993. 